\title{
Factors contributing to low readiness and capacity of culturally diverse participants to use the Australian national bowel screening kit
}

\section{Lyn Phillipsonn, a,f, Leissa Pittsc, ${ }^{c, d}$, Julie Halla and Tameika Tubaroc,e}

a Faculty of Social Sciences, University of Wollongong, NSW, Australia

b Australian Health Services Research Institute, University of Wollongong, NSW, Australia

c Illawarra Shoalhaven Local Health District, Wollongong, NSW, Australia

${ }^{d}$ Multicultural and Refugee Health Service, Wollongong, NSW, Australia

e Illawarra Cancer Care Centre, Wollongong Hospital, NSW, Australia

† Corresponding author: Iphillip@uow.edu.au

\section{Article history}

Publication date: March 2019

Citation: Phillipson L, Pitts L, Hall J, Tubaro T. Factors contributing to low readiness and capacity of culturally diverse participants to use the Australian national bowel screening kit. Public Health Res Pract. 2019;29(1):e28231810. First published: 30 August 2018. https://doi.org/10.17061/phrp28231810

\section{Key points}

- Culturally and linguistically diverse populations are less ready and able to use the testing kits currently distributed as part of Australia's National Bowel Cancer Screening Program

- Barriers to completion include a lack of information in community languages, poor kit design and poorly sequenced, complex kit instructions

- Kit usability could be improved through better design, plain-language sequenced instructions with pictorials, promotion of the kit, education in community languages, and involvement and endorsement by general practitioners

\section{Abstract}

Objectives: Bowel screening is an effective way to promote early detection of bowel cancer. Culturally and linguistically diverse (CALD) people face considerable barriers to screening. This qualitative study explored perceptions towards, and usability of, Australia's national bowel screening kit with members of two migrant communities.

Methods: Thirty-three people (aged 50-79 years) from Serbian and Macedonian communities in the Illawarra region in New South Wales, Australia, participated in one of five interactive focus group sessions. Sessions used innovative 'customer journey' techniques to understand participants' experience of each step of the faecal occult blood test process. Participants discussed knowledge of bowel cancer and attitudes to screening, and participated in a collective mock use of a test kit. Sessions were audio recorded, transcribed and thematically analysed by two researchers in collaboration with bicultural health workers.

Results: Multiple factors contributed to low readiness and capacity to use the kit, including limited promotion of the program in community languages, complicated and poorly sequenced kit instructions, and confusion around the order and labelling of kit components. Participants suggested several ways to improve kits to improve uptake by CALD communities.

Conclusion: Simplified and targeted promotion of bowel screening programs in community languages, and improved kit design, may support participation of CALD populations in screening programs. 


\section{Introduction}

Bowel (colorectal) cancer is the third most common cancer globally ${ }^{1}$, and the second leading cause of cancer-related deaths in Australia, New Zealand and the US. ${ }^{2-4}$ Australia and New Zealand have the highest incident rates for colorectal cancer in the world.

Population screening programs using the faecal occult blood test (FOBT) or faecal immunochemical tests are supported in Australia, New Zealand, the UK and many European nations..$^{5-7}$ Screening reduces mortality from colorectal cancer ${ }^{8}$, but low screening rates limit the effectiveness of programs to reduce disease burden. ${ }^{5}$ In 2013-14, only $36 \%$ of invitees to the Australian National Bowel Cancer Screening Program (NBCSP) returned a completed FOBT kit. ${ }^{9}$

People from culturally and linguistically diverse (CALD) backgrounds have poorer cancer outcomes ${ }^{10}$ and experience lower rates of bowel cancer screening than the general population in Australia. ${ }^{9,10}$ Although NBCSP participation rates for CALD populations are difficult to determine, differences have been shown between these populations and the general population in knowledge of, perception of, and health behaviours towards colorectal cancer and bowel screening in Australia and the US. ${ }^{11,12}$ Factors affecting uptake of screening include insufficient knowledge, perceptions that the test is unpleasant, language and literacy barriers, fatalistic cancer views, low general practitioner (GP) recommendations, and spiritual beliefs. ${ }^{13,14}$ People can also respond to screening information in different ways because of differences in literacy (e.g. health and language) and cognitive processes (e.g. decision making). ${ }^{15}$ Although additional research is needed to identify how information in FOBT kits can improve informed decision making ${ }^{16}$, the focus of this paper is on exploring the usability of Australia's NBCSP FOBT kit among two CALD groups.

\section{Methods}

A convenience sample was recruited of men and women older than 50 years who identified as members of the Macedonian and Serbian communities from the Illawarra region in New South Wales (NSW), Australia. These communities collectively represent more than $20 \%$ of the total CALD non-English speaking population in the Illawarra ${ }^{17}$ and also occupied a disproportionate 'count of stay' for cancer hospital admissions from 2007 to 2012. ${ }^{18}$ Bicultural healthcare workers provided information sheets, consent forms and a verbal explanation of the study to potential participants of screening age within their known community networks in their preferred language. Discussion groups of 60-90 minutes were conducted in familiar community venues by experienced female researchers trained in qualitative methods ( $\mathrm{LPh}$ and LPi). Bicultural workers and accredited healthcare interpreters were also present to assist ${ }^{18}$, although all participants were able to speak some English. The interpreter translated any instructions and questions posed by the facilitator in English that required clarification. Answers given by some group members were difficult for them to express in English, so were translated to ensure that the researcher understood the intended meaning. Each group (five or six participants) was supported using a semistructured interview guide. They were also provided with an NBCSP FOBT kit and asked to examine the contents, work collectively to complete a 'mock test' using a camp toilet, and describe their interactions with the kit. The process used a 'customer journey' methodology to build an understanding of each step taken to complete the task. ${ }^{19,20}$ All participants initially used the Englishlanguage instructions, but translated instructions were also provided when necessary to support successful completion of the test.

Audio recordings of the English spoken within the groups by the facilitator, participants and interpreter were professionally transcribed. Each author also made field notes about group interactions with the FOBT kit. Transcriptions and field notes were imported into Dedoose qualitative analysis software (Los Angeles, CA: Dedoose; Version 7). Initial analysis by two researchers (LPh and TT) used an inductive approach for identifying key steps in the FOBT completion process to form the coding tree. Final analysis was reviewed with the rest of the research team until agreement was reached. Ethics approval was obtained from the University of Wollongong Human Research Ethics Committee (HE12/295).

\section{Results}

Thirty-three participants (aged 50-79 years) participated in one of five interactive groups between October 2014 and March 2015. The groups comprised 11 Macedonian (5 male and 6 female) and 22 Serbian (10 male and 12 female) participants. Five key stages in the customer journey of completing an NBCSP FOBT were identified: preparation, following kit instructions, navigating kit components, completing the patient information form, and feedback and follow-up. Within each of these stages, specific barriers and enablers to completing the FOBT emerged.

\section{Preparation}

Some participants reported gaps in their knowledge of bowel cancer screening, the NBCSP, what an FOBT was, who should complete it, and the potential benefits of completing the test:

I have never seen or heard of these tests before... that is why I came along today ... to learn if this is something I need to worry about. (Female group, Macedonian) 
Other participants recalled receiving the kit in the mail but did not know what it was, or why they had received it. Motivation and readiness to undertake the FOBT were reportedly low in these circumstances:

Just a surprise ... because we received it from the government. Yeah, we didn't know what it was when it came in the mail ... so we didn't understand that it was important to use it. (Female group, Macedonian)

Some participants who reported good health believed the test was not necessary because they had no symptoms of illness. Participants recalled relying on their GP to manage and direct required medical tests. Selftesting using a kit that came in the mail was reportedly not a familiar behaviour:

When you don't feel anything's wrong with you then these tests seem to be unnecessary for you because you don't, in a sense, you don't have symptoms ... so why would you do it? It's just not necessary. (Mixed gender group, Serbian)

See these things ... we should go about with our doctors. So when you go to your doctor, your doctor would advise you and you would organise it ... so this is not necessary ... and a bit strange to get something like this in the mail. (Female group, Serbian)

A number of participants recalled having had colonoscopies without prior FOBT, as recommended by their GP:

See I skipped completely this first test [the FOBT] because after 50 years it's usually recommended [by your doctor] for you to do a colonoscopy, so I went and had a colonoscopy first. (Female group, Serbian)

A lot of people also do not believe that it [an FOBT] is as accurate as a colonoscopy ... because this is what our doctors have told us. (Female group, Serbian)

A small group reported positive bowel screening attitudes. Participants who had screened for other conditions (e.g. mammograms, Pap smears) also reported having used, or having an intention to use, the test:

I received it, it was free, it meant somebody else is looking after me other than myself ... so I thought why not and I did it ... I also always do the mammogram too. (Mixed gender group, Serbian)

Factors reported as improving motivation and readiness included GP endorsement, and recall of in-language health promotion messages about bowel screening and the NBCSP in ethnic media and at local community events. Exposure to bowel screening promotions in community languages also prompted conversations about bowel screening:
One of the radio announcers [on the ethnic radio station] was talking about it so we heard about it there. Also, then after listening to the radio, and you receive this package and then you go and see your doctor. Along the way you get the information that is necessary to convince you to do it.

(Female group, Macedonian)

\section{Following kit instructions}

Usability of the kit was observed to be limited by the complexity of instructions and tasks. Difficulties encountered included the flow of tasks, time frames for each step (e.g. times between sample collection), storage (e.g. fridge or cool place), postage (e.g. mail box vs post office) and other practical concerns (e.g. flushability of stool collection sheet):

This is very confusing ... do I have to store it in the fridge or is the cupboard OK? It also doesn't make sense about the post box or the post office ... I will never be sure to get this right! (Female group, Macedonian)

The paper can block your toilet so why not a container ... a container is better. (Male group, Serbian)

Researchers observed that some participants were unable to read the English-language instructions, and concluded that low English literacy contributed to low comprehension about what the kit was for, as well as difficulties following the instructions:

Is this going to be sent to all multicultural people? Why didn't the government translate this paper? Some people can't read it; the first barrier is finding out what this kit is about. [Firstly] we need to get someone to translate this [for us], barrier number one, which will take time ... we will have to call people [to help] ... so people will just throw it to the side somewhere. (Male group, Serbian)

In all groups, it was necessary for the researchers to introduce translated instructions to support completion of the 'mock' FOBT test. Before this, participants were asked to identify how translated instructions could be accessed. Some identified online sources, but others could not. Many reported that they would not be able to access translated instructions because of the length of the website address, or limited computer access:

I'm too old to access the internet. (Mixed gender group, Serbian)

Not everybody knows how to use a computer, that's if you have a computer, not everyone has a computer. (Male group, Macedonian) 
Even when translated, the volume and complexity of written instructions posed significant barriers for those with limitations in their ability to read. These participants were reliant on other group members who were able to read to complete the activity.

In response, participants suggested a focus on pictorial representations with briefer text to support test completion:

So, not just for the Serbian language, but for every other language - we are not just the only community here with a different language - maybe would be good ... to have more pictures there, so, where you can see what the people are doing. It's easier to follow, and that way, even with a language barrier you might be able to get a picture of how to do that. (Male group, Serbian)

You're talking about people who can't read, meaning read Serbian - read at all. (Mixed gender group, Serbian)

\section{Kit components}

Some participants commented on the use of the word 'cancer' on the front of the test box. They explained that cancer was related to fear and stigma, and that the arrival of a clinical-looking kit for cancer caused anxiety:

The word cancer and the logo and everything, it doesn't look friendly ... it looks scary and makes me worry ... (Female group, Macedonian)

On opening the kit, some participants reported feeling overwhelmed. It was not clear to them how the information sheets and labels related to other kit components (e.g. sample tubes, collection sheet). Participants were unsure where to start and in which order the tasks needed to be completed. Instructions on the stool sample collection sheet were 'lost' once the sheet was placed in the toilet. Participants suggested design improvements to reduce confusion, such as visual cues, colour coding, and numbering of components and their corresponding instructions:

It actually has to be in simple language.

There are many that have ... not good English

and we have to have step 1, step 2, step 3.

(Female group, Macedonian)

\section{Patient information form}

Participants reported that they felt daunted by the length of the patient information form. Some questioned why the information could not be 'pre-populated'. Although family members, GPs or multicultural workers were called on to assist with completing forms, this could not always occur within the required time frame for posting the sample to pathology:
Yes. We don't know English enough to fill out a lot of them. Even if we did speak English, sometimes some things are a little bit too complicated. It's hard to understand the questions ... and we can't always get help in time. (Female group, Macedonian)

That's why I went to my GP; my GP filled it out for me. (Female group, Macedonian)

During the practical activity, participants frequently sealed the sample envelope, believing they had completed all tasks. However, many groups failed to include their participant information form in the envelope. It was suggested that completion of paperwork should be 'step 1' in the flow of tasks:

These [forms] should be done at the start, the details in the front, then the practical after ... filling out forms, collecting procedure, then sending procedure ... but everything is mixed up, it should be more simple for people, for ordinary people that are not medically educated. (Male group, Serbian)

\section{Feedback and follow-up}

Participants reported not understanding who would receive FOBT results (e.g. themselves, their GP or both), how the results would be communicated or the reporting time frame. Anxiety surrounded the length of time participants might wait because of fear and anticipation of bad news. To reduce this stress, participants reported wanting information on expected time frames and actions they should take if results were positive:

We know it goes to this address to be processed but who is going to worry about this? When are the results back? Who is going to get results, how long will it take we don't know, is there a phone number, if there is an emergency contact if we need to know results or pick them up from somewhere? We need to know this or otherwise we will be too worried ... (Male group, Serbian)

\section{Recommendations to improve usability}

Participants' responses were used to inform a set of recommendations (see Table 1) to improve usability and uptake of the FOBT kit. These include simplification of instructions, reduction of text, use of pictorials, and adaptations such as colour coding and numbering. Community members also reported the need for targeted promotion of the NBCSP in community languages to improve preparedness to complete the test. 
Table 1. Recommendations to improve use of the NBCSP FOBT kit

\begin{tabular}{|c|c|c|}
\hline Themes & Issues & Recommendations \\
\hline $\begin{array}{l}\text { Preparation and } \\
\text { readiness }\end{array}$ & $\begin{array}{l}\text { - Low awareness of NBCSP and FOBT } \\
\text { - Low belief in efficacy of FOBT } \\
\text { - Stigma and fear of cancer }\end{array}$ & $\begin{array}{l}\text { - NBCSP plain-language campaigns and translated resources } \\
\text { - } \quad \text { ia ethnic media and GPs } \\
\text { - } \quad \text { GPs as key opinion leaders to endorse kit use }\end{array}$ \\
\hline Kit instructions & $\begin{array}{l}\text { - } \text { Text-heavy, complex language } \\
\text { - Limited use of pictorials } \\
\text { - } \quad \text { Lack of flow and clarity in tasks } \\
\text { required } \\
\text { - } \quad \text { No checklists to assist process } \\
\text { - } \quad \text { Problems accessing translated } \\
\text { instructions } \\
\text { - Limited literacy (English and first } \\
\text { language) }\end{array}$ & $\begin{array}{l}\text { - } \quad \text { Plain-language instructions on a single brochure } \\
\text { - Increased use of pictorials to support simplified text } \\
\text { - } \quad \text { Improved flow and sequencing of instructions } \\
\text { - } \quad \text { Checklist to improve completion } \\
\text { - } \quad \text { Colour coding and numbering to create visual links between } \\
\text { instructions and kit components } \\
\text { - } \quad \text { CALD user testing of all materials } \\
\text { - } \quad \text { Improved access to translated materials } \\
\text { - } \quad \text { support access to in-language instructions }\end{array}$ \\
\hline Kit components & $\begin{array}{l}\text { - Confronting packaging } \\
\text { - Kit contents not clearly ordered or } \\
\text { linked }\end{array}$ & $\begin{array}{l}\text { - Improved kit appearance and labelling to promote simplicity } \\
\text { - } \text { Cond ease of use } \\
\text { compontent, clear and cohesive design, linking instructions and } \\
\text { - Adaptations (e.g. colour coding, numbering) } \\
\text { - Adaptation of components to cater for low dexterity }\end{array}$ \\
\hline $\begin{array}{l}\text { Patient } \\
\text { information form }\end{array}$ & $\begin{array}{l}\text { - High and repetitive demands on } \\
\text { consumers to handwrite information } \\
\text { - Postage instructions unclear }\end{array}$ & $\begin{array}{l}\text { - Instructions to complete information form first } \\
\text { - Redesign of form for simplicity and ease of use } \\
\text { - } \text { Prepopulation of forms and labels (e.g. name, address) } \\
\text { - Improved clarity of postage and handling requirements }\end{array}$ \\
\hline $\begin{array}{l}\text { Feedback and } \\
\text { follow-up }\end{array}$ & $\begin{array}{l}\text { - Lack of clarity of mechanism and time } \\
\text { frame for receipt of results }\end{array}$ & $\begin{array}{l}\text { - Improved post-test communications } \\
\text { - Test results section included in the plain-language instructions } \\
\text { - } \text { Promotion of NBCSP helpline and telephone interpreter service } \\
\text { - Use of national interpreter symbol } \\
\text { - GPs and Primary Health Networks to promote follow-up }\end{array}$ \\
\hline
\end{tabular}

CALD = culturally and linguistically diverse; FOBT = faecal occult blood test; GP = general practitioner; NBCSP = National Bowel Cancer Screening Program

\section{Discussion}

This study used innovative customer journey techniques to understand the practical experience of members of two CALD communities in using an NBCSP FOBT kit. Most involved showed low awareness of, and readiness to complete, the test and related forms. Lack of knowledge about bowel cancer risk, symptoms, survival rates and the efficacy of the FOBT reportedly diminished participants' readiness to complete the test. Stigma and fear related to cancer and cancer screening practices in general, which have been identified in previous research, were also reported. ${ }^{13,14}$ In the discussion groups, readiness to use the FOBT was observed to be greater for participants who reported prior screening experience (e.g. BreastScreen), had an ability to read instructions in English, reported discussing FOBT testing with their GP, and reported being exposed to promotion via ethnic media or in-language community education. The extent to which information in FOBT kits supports informed choices may be another factor affecting the low motivation we observed and thus the 'preparation and readiness' phase for participants. ${ }^{16}$

A systematic review of cancer interventions targeting CALD communities found that a lack of targeted social marketing in diverse communities contributed to low awareness and uptake of cancer screening and prevention messages. ${ }^{21}$ On the other hand, coordinated campaigns have been effective in CALD communities in which cancer is stigmatised ${ }^{22}$, and should be systematically supported at a population level. Specifically, these results suggest the need for increased NBCSP promotion in diverse languages, via appropriate media channels (e.g. ethnic radio). Campaign activities should also improve access to plain-language and translated instructions, and provide opportunities to practise using the kit. 
At present, distribution of NBCSP kits in Australia occurs by birthdate, with limited reference to geographic location. ${ }^{9}$ However, consideration of resident location (by postcode or region) may increase the capacity for campaigns to target geographic areas (and thus CALD groups within these communities) at certain times to improve the effectiveness of campaigns.

GP endorsement - either face to face, or by letter or phone - should be used alongside community promotion as part of coordinated campaign activities.

This study highlights that kit instructions were perceived as difficult because of text complexity, and volume and sequencing of task information. The delivery of key instructions across multiple leaflets led to confusion about the order of steps. Participants who could not read English were unable to read instructions or access translated materials from the NBCSP website. Often, participants reported low digital literacy, no access to a computer, or difficulties entering the long website address. These problems are likely to have an impact in other CALD populations and in populations with low literacy. This highlights the need for bowel screening programs to improve availability, access and promotion of translated instructions, as well as provide helplines and telephone interpreter services. Participants recommended simpler language and the use of pictures. These have been used previously to increase both attention to, and recall of, health information. ${ }^{23}$

Participants reported difficulties knowing where to start the test, and matching components (e.g. collection tubes, collection sheets, probes, labels) with corresponding instructions. This led to errors in completion of the test, such as placing labels on the wrong tube. Use of some items required manual dexterity beyond the capacity of some participants. Messages around keeping samples cool and where they should be posted were also frequently missed or misunderstood. This highlights the need for ergonomics and 'human-centred' design to support the development of simple, comprehensible tests for use by the whole population. ${ }^{24}$ The design must consider people with dexterity, sight or other physical limitations, and the substantial proportion of the population with low literacy. ${ }^{25}$

Participants found the patient information form challenging. Barriers included limited ability to read English, the number of questions, and repetition on multiple patient instruction sheets. This led to questions being overlooked as an important final step in the process. Many considered it more logical to complete the form as the first step. Checklists have long been used to support medical and nonmedical processes as cognitive aids to guide users through task completion. ${ }^{26}$ Participants felt that the FOBT kit should provide a mechanism for them to check whether they had successfully completed the process.

Finally, many participants demonstrated a lack of understanding about the timing, processing and receipt of test results, as well as what type of support they would receive if they needed follow-up care.
Along with pre-existing or other anxiety around cancer testing, these areas were a significant barrier. They highlight the need for greater integration of the NBCSP FOBT with primary care settings to promote uptake ${ }^{27}$ and to reduce delays in follow-up care. ${ }^{28}$

Overall, recommendations provided by participants are similar to principles used in other health literacy tools and guidelines (e.g. Patient Education Materials Assessment Tool). ${ }^{29}$ The recommendations highlight the need to extend the application of these principles to the design of health test kits, as well as other patient information resources.

\section{Limitations}

Because of the small sample used and the limited demographic information collected, there are some limitations to the generalisability of the findings of this study to other CALD groups. Although some issues identified may apply to other groups, this will depend on other factors (e.g. education, age, cultural factors) Further research in this area is required, not just with CALD groups but also with groups with limited literacy and education in English, who may also experience usability issues with the current FOBT kit.

\section{Conclusion}

Multiple factors contributed to the low readiness and capacity of participants to use the NBCSP FOBT kit. These included limited ability to read English or translated instructions, perceived lack of endorsement of the kit by GPs and, in some cases, limited belief in the efficacy of the FOBT. Limited promotion in community languages, poor kit design and poorly sequenced, complex instructions were also barriers to completion. Usability could be improved through better kit design, and plain-language sequenced instructions with improved pictorials. Uptake could also be improved through positive messages about bowel screening efficacy; promotion of the kit in community languages; greater access to translated instructions, and in-language community education and support; and improved GP endorsement. These recommendations are timely, considering the current tender process to redesign the NBCSP FOBT kit.

\section{Acknowledgements}

This article is based on research funded by the Illawarra Shoalhaven Local Health District (NSW Health). The funder had no role in the design or findings of the research. The research team would like to acknowledge the bicultural health workers from the Illawarra Shoalhaven Local Health District who played a role in the conduct of this research (Anica Petkovski and Zaga Trkulja) and also Jon Emery (University of Melbourne) who provided expert comment on versions of the manuscript prior to submission. 


\section{Peer review and provenance}

Externally peer reviewed, not commissioned.

\section{Competing interests}

None declared.

\section{Author contributions}

LPh led the overall project and conceptualisation of the study design. LPi and $\mathrm{JH}$ contributed to the study design. $\mathrm{LPh}, \mathrm{LPi}$ and $\mathrm{JH}$ facilitated the discussion groups and contributed to data analysis. TT was responsible for the initial coding and analysis of the data. All authors contributed to the writing and editing of the manuscript.

\section{References}

1. International Agency for Research on Cancer. France: IARC; 2018. GLOBOCAN 2012: Estimated cancer incidence, mortality and prevalence worldwide in 2012; 2012 [cited 2017 Jul 28]; [about 5 screens]. Available from: globocan.iarc.fr/Pages/fact_sheets_cancer.aspx

2. Australian Institute of Health and Welfare. Cancer in Australia: an overview 2012. Canberra: AlHW; 2012 [cited 2017 Jul 28]. Available from: www.aihw.gov.au/getmedia/ efaa639f-d6b8-4e19-8d38-bcba7646360e/14757.pdf. aspx?inline $=$ true

3. Cancer Research UK. London: Cancer Research UK. Bowel cancer statistics. London: Cancer Research UK: 2017 [cited 2017 Aug 4]; [about 3 screens]. Available from: www.cancerresearchuk.org/health-professional/ cancer-statistics/statistics-by-cancer-type/bowel-cancer

4. Ministry of Health. Wellington: New Zealand Ministry of Health; 2018. Bowel Cancer; 2017 [cited 2017 Aug 4]; [about 4 screens]. Available from: www.health.govt.nz/ your-health/conditions-and-treatments/diseases-andillnesses/bowel-cancer

5. Bulliard JL, Garcia M, Blom J, Senore C, Mai V, Klabunde C. Sorting out measures and definitions of screening participation to improve comparability: the example of colorectal cancer. Eur J Cancer. 2014;50:(2):434-46.

6. Cancer Research UK. London: Cancer Research UK. Bowel cancer screening [cited 2017 Aug 4]; [about 5 screens]. Available from: www.cancerresearchuk.org/ about-cancer/bowel-cancer/getting-diagnosed/screening

7. Ministry of Health. Wellington: New Zealand Ministry of Health; 2018. National Bowel Screening Programme [cited 2017 Aug 4]; [about 2 screens]. Available from: www.health.govt.nz/our-work/diseases-and-conditions/ cancer-programme/bowel-cancer-programme/nationalbowel-screening-programme
8. Hewitson P, Glasziou P, Watson E, Towler B, Irwig L. Cochrane systematic review of colorectal cancer screening using the fecal occult blood test (hemoccult): an update. Am J Gastroenterol. 2008;103(6):1541-9.

9. Australian Institute of Health and Welfare. National Bowel Cancer Screening Program: monitoring report 2017. Canberra: AlHW; 2017 [cited 2018 Jun 27]. Available from: www.aihw.gov.au/getmedia/7c28bbcb-da33-493d974c-81706c9ce76e/20839.pdf.aspx?inline=true

10. Cancer Institute NSW. Sydney: Cancer Institute NSW: 2018. Multicultural communities [cited 2017 Aug 4]; [about 6 screens]. Available from: www.cancer.nsw.gov. au/cancer-plan/focus-areas/cald-communities

11. Koo JH, Arasaratnam MM, Liu K, Redmond DM, Connor SJ, Sung JJY, Leong RW. Knowledge, perception and practices of colorectal cancer screening in an ethnically diverse population. Cancer Epidemiol. 2010;34(5):604-10.

12. Shahidi N, Homayoon B, Cheung W. Factors associated with suboptimal colorectal cancer screening in US immigrants. Am J Clin Oncol. 2013;36(4):381-7.

13. Javanparast $S$, Ward $P$, Carter S, Wilson S. Barriers to and facilitators of colorectal cancer screening in different population subgroups on Adelaide, South Australia. Med J Aust. 2012;196(8):521-3.

14. Javanparast S, Ward P, Young G, Wilson C, Carter S, Misan $\mathrm{G}$, et al. How equitable are colorectal cancer screening programs which include FOBTs? A review of qualitative and quantitative studies. Prev Med. 2010;50(4):165-72.

15. Smith S, Kearney P, Trevena L, Barratt A, Nutbeam D, McCaffery KJ. Informed choice in bowel cancer screening: a qualitative study to explore how adults with lower education use decision aids. Health Expect. 2014;17(4):511-22.

16. Howard K, Salkeld G. Home bowel cancer tests and informed choice - is current information sufficient? Aust N Z J Public Health. 2003;27(5):513-6.

17. Australian Bureau of Statistics. Report from Census 2011. Language spoken at home by Sex for the Illawarra region (107). Canberra: ABS; 2011.

18. Illawarra Shoalhaven Local Health District. Confidential report on cancer length of stay by language group in Wollongong Hospital from (2007-2012). Local data request from Multicultural and Refugee Health Service. Wollongong: ISLD; 2012. [Unpublished].

19. Liamputtong P. Focus group methodology: principle and practice. London: Sage Publications Ltd; 2011.

20. Crosier A, Handford A. Customer journey mapping as an advocacy tool for disabled people: a case study. Social Marketing Quarterly. 2012;18(1):67-76. 
21. Johnston $\mathrm{R}$, Kong $\mathrm{X}$. The customer experience: a roadmap for improvement. Managing Service Quality: An International Journal. 2011;21(1):5-24.

22 Phillipson L, Larsen-Truong K, Jones S, Pitts L. Improving cancer outcomes among culturally and linguistically diverse communities: a rapid review of the literature. Wollongong: University of Wollongong, 2012 [cited 2018 Jun 27]. Available from: ro.uow.edu.au/cgi/viewcontent. cgi?article=1485\&amp; context=sspapers

23. Phillipson L, Hall J, Pitts L, Hunt T. Project Good News - engaging priority CALD communities to reduce the stigma associated with cancer. Presented at the Innovations in Cancer Services and Care NSW Conference; 2013 Aug 23; Sydney, NSW.

24. Houts PS, Doak CC, Doak LG, Loscalzo MJ. The role of pictures in improving health communication: a review of research on attention, comprehension, recall, and adherence. Patient Educ Couns. 2006;61(2):173-90.

25. Weinger MB, Wiklund ME, Gardner-Bonneau DJ. Handbook of human factors in medical device design. Boca Raton: CRC Press; 2011.
26. Australian Bureau of Statistics. Canberra: ABS; 2018. Programme for the International Assessment of Adult Competencies, Australia, 2011-2012. Canberra: ABS; 2013 [cited 2016 Dec 14]. Available from: www.abs. gov.au/ausstats/abs@.nsf/Lookup/4228.0main+featur es992011-2012

27. Clouston K, Katz A, Martens PJ, Sisler J, Turner D, Lobchuk M, et al. Does access to a colorectal cancer screening website and/or a nurse-managed telephone help line provided to patients by their family physician increase fecal occult blood test uptake? Results from a pragmatic cluster randomized controlled trial. BMC Cancer. 2014;14:263.

28. Ferrat E, Le Breton J, Veerabudun K, Bercier S, Brixi Z, Khoshnood B, et al. Colorectal cancer screening: factors associated with colonoscopy after a positive faecal occult blood test. Br J Cancer. 2013;109(6):1437-44.

29. Shoemaker SJ, Wolf MS, Brach C. Development of the Patient Education Materials Assessment Tool (PEMAT): a new measure of understandability and actionability for print and audiovisual patient information. Patient Educ Couns. 2014;96(3):395-403.

\section{Copyright: (C) (i) (3) (2)}

(C) 2018 Phillipson et al.This article is licensed under the Creative Commons Attribution-NonCommercial-ShareAlike 4.0 International Licence, which allows others to redistribute, adapt and share this work non-commercially provided they attribute the work and any adapted version of it is distributed under the same Creative Commons licence terms. See: www.creativecommons.org/licenses/by-nc-sa/4.0/ 